\title{
Embates acerca da ideia de justiça social em relação a conflitos sociais e desigualdades
}

\author{
Alex Pizzio \\ Universidade Federal do Tocantins / Programa de Pós-Graduação em Desenvolvimento Regional \\ Palmas / TO - Brasil
}

\begin{abstract}
A justiça social é um tema controverso, de amplo debate no âmbito das ciências sociais. Seu caráter impreciso decorre das diversas abordagens encontradas acerca do tema, que ora a concebem como derivada de um procedimento institucional vinculado à justiça formal e de base material, ora a concebem como procedente da conduta individual vinculada à ética e à moral. Nessa perspectiva, a temática demanda um conjunto de questionamentos. Quando se fala de justiça social, quais questões, exatamente, estão envolvidas? Quais elementos a constituem? Quando se pode dizer que uma pessoa ou instituição é justa ou injusta? Em outras palavras, quando se sabe ou se pode afirmar que as ocorrências cotidianas refletem arranjos sociais justos? Essas e outras indagações são de extrema relevância quando se evolui no debate acerca da gestão e da implementação de políticas públicas que têm por meta alcançar um patamar elevado de justiça social. O objetivo deste artigo é contribuir para o enriquecimento desse debate, incluindo elementos que consideramos importantes para o avanço das políticas públicas em sociedades como a brasileira.
\end{abstract}

Palavras-chave: justiça social; reconhecimento; redistribuição; paridade participativa.

\section{Enfrentamientos con la idea de justicia social en relación a los conflictos sociales y las} desigualdades

La justicia social es un tema polémico, de amplio debate dentro de las ciencias sociales. Su carácter inexactos tallos de diversos enfoques encontraron sobre el tema, que el diseño como derivados de un procedimiento institucional vinculado a la justicia formal y material de base, orar a concebir como provenientes de la conducta individual ligado a la ética y la moral. En esta perspectiva, el tema exige un conjunto de preguntas. ¿Cuando se habla de justicia social, que, exactamente, están involucrados? ¿Que forman los elementos? ¿Cuando se puede decir que una persona o institución es justa o injusta? ¿En otras palabras, cuando usted sabe o no puede decir que ocurrencias cotidianas reflejan acuerdos sociales justos? Estas y otras preguntas son de la máxima importancia cuando se desenvuelve en el debate sobre la gestión y ejecución de políticas públicas que tienen el objetivo de alcanzar un alto

DOI: http://dx.doi.org/10.1590/0034-7612127748

Artigo recebido em 7 dez. 2013 e aceito em 1ำ mar. 2016.

(c) (1) 
nivel de justicia social. El propósito de este artículo es contribuir al enriquecimiento de este debate, incluyendo elementos que consideramos importantes para el avance de las políticas públicas en sociedades como la brasileña.

Palabras clave: justicia social; reconocimiento; redistribución; paridad participativa.

Clashes over the idea of social justice in relation to social conflicts and inequalities

Social justice is a controversial topic and one that fosters a wide-ranging debate within the milieu of the social sciences. Its ambiguous nature is mainly due to the existence of a number of different ways of approaching the subject. Some see it as being derived from an institutional procedure that is bound to formal justice with a material foundation, while others see it as deriving from individual behavior bound to ethics and morality. From this perspective, the topic demands a number of questions. When one talks of social justice, what precisely are the questions involved? What are its constituent elements? At what point can one state that a person or institution is just or unjust, fair or unfair? In other words, when is an individual aware or able to state categorically that the events of his/her daily life do indeed reflect a fair social system? These and other questions are of the utmost importance when one moves ahead in the debate regarding the management and implementation of public policies aimed at achieving a high level of social justice. The purpose of this article is to contribute to the enrichment of this debate by including elements considered important to the advancement of public policies in societies like that of Brazil.

KEYWORDs: social justice; recognition; redistribution; participatory parity.

\section{Justiça social: afinal, do que se trata?}

Quando se fala de justiça social, quais questões, exatamente, estão envolvidas? Quais elementos a constituem? Quando se pode dizer que uma pessoa ou instituição é justa ou injusta? Em outras palavras, quando se sabe ou se pode afirmar que as ocorrências cotidianas refletem arranjos sociais justos? A temática tem sido objeto de reflexão desde a Antiguidade. Em sua vertente mais difundida, a ideia de justiça tem sido tratada em termos de uma justiça distributiva e encontrado seu princípio fundamental na máxima "Dê a cada indivíduo o que lhe é devido", seja com base em suas necessidades, em seu mérito ou em suas escolhas. Ao longo do tempo, a figura da balança tem servido de representação simbólica da imparcialidade ante as reivindicações por justiça. Trata-se de perspectivas históricas, que variam conforme os valores e os bens dominantes em cada sociedade, portanto sujeitas às ideologias, uma vez que se assentam em concepções de mundo que emergem de relações sociais concretas.

Tais apontamentos iniciais demonstram que o enfrentamento dos aspectos que envolvem a ideia de justiça social constitui uma tarefa árdua, da mesma forma que o tratamento teórico-conceitual da temática ocorre em um terreno pantanoso. Um breve balanço acerca das sociedades de modo geral evidencia que, em muitas delas, as desigualdades não apenas são aceitas, mas encontram respaldo e legitimidade no ordenamento social. Sem pretender esgotar a pluralidade dos elementos que norteiam o debate referente à ideia de justiça na 
atualidade, pretende-se destacar alguns aspectos conceituais relevantes para a discussão que se realizará.

O primeiro ponto a destacar diz respeito às ideias de justiça formal e material. A ideia de justiça formal encontra-se amplamente alicerçada no pressuposto de que as distribuições devam ser realizadas com base em critérios ou regras existentes ou aceitas. Geralmente aparece identificada com a justiça jurídica e/ou individual e implica igualdade formal, caso se entenda que, em uma sociedade, todas as pessoas devam ser tratadas segundo as mesmas regras. Nos regimes democráticos, os direitos civis e políticos presentes na ideia de cidadania exemplificam bem essa questão. A justiça material, por sua vez, relaciona-se com a identificação de critérios distributivos adequados em relação à riqueza socialmente produzida e aos seus benefícios (Campbell, 1996).

O segundo aspecto refere-se à ideia de que a justiça se apresenta vinculada a uma pluralidade de situações. Segundo Agnes Heller (1998), existe uma variedade de atos que podem ser considerados justos ou injustos. Podem ser atos de julgamento, os que concedem ou negam alguma coisa, de castigo ou premiação, de distribuição, entre outros. A consequência imediata dessa pluralidade de situações reside na concepção de que o tratamento igualitário, concebido como fonte de justiça, acaba por expressar relações de dois tipos.

Em um sentido, o ato justo ou injusto surge como resultante da forma de tratamento dispensado por um indivíduo a outro em situações cotidianas. É correto afirmar que a qualificação desse ato depende da maneira como os membros de uma comunidade ou agrupamento aplicam as regras e normas uns aos outros nas interações sociais. O modo diferenciado com que são tratadas pessoas diferentes em situações idênticas constitui a variável mais significativa dessa questão. Nessa perspectiva teórica, a justiça é entendida em termos de virtude pessoal, vinculada ao agir correto no dia a dia.

Por outro lado, as situações de justiça e injustiça também se referem à aplicação de critérios institucionais, em que as instituições básicas, políticas, econômicas e sociais devem ser avaliadas em seu fundamento. Quando se analisa esse aspecto da temática, reflete-se sobre um conjunto de questões que envolvem, além de elementos éticos e morais, aspectos materiais e simbólicos. De forma contingente, esse ponto tende a ficar intrincado à medida que se constata que as avaliações das instituições sociais e políticas funcionam em numerosas relações de interdependência ou de subordinação. Em decorrência, a discussão sobre o que é justo ou injusto, particularmente em relação à partilha de recompensas e ônus sociais, encontra-se permeada pelo debate sobre a igualdade e a desigualdade na distribuição de bens sociais. Heller e Fehér (1998:174) destacam que "igualdade e desigualdade não são uma substância; tanto igualdade quanto desigualdade são constituídas na aplicação de regras e normas, e só por elas". Trata-se da razão pela qual é possível falar que as ideias de justiça são princípios gerais de comparação e classificação, pois as ações humanas só podem ser justas ou injustas se puderem ser comparadas e, incidentalmente, classificadas.

Posição semelhante é apresentada pelo filósofo canadense Will Kymlicka. O autor destaca que "temos obrigações morais mútuas, das quais algumas são de responsabilidade pública 
- impostas por meio de instituições públicas — e outras são de responsabilidade pessoal — envolvendo regras de conduta pessoal" (Kymlicka, 2006:8). Nesse sentido, ressalta-se que,

ainda que seja necessária a virtude pessoal da justiça, ou seja, o bem agir das pessoas para a realização das relações sociais justas, tem preeminência, sistematicamente, a justiça entendida como critério de crítica institucional e expressa em princípios de justiça social. Com efeito, os homens agem, em grande parte, num contexto institucional constituído de regras jurídicas e outras. Não é tanto o agir do indivíduo como tal, mas são, em primeira linha, os efeitos das instituições sociais, em seu conjunto, que determinam o convívio humano, bem como a distribuição de bens importantes, e influem profundamente nas perspectivas de vida de cada membro da sociedade. [Kley, 1997:354-355]

Com o propósito de melhor compreender os efeitos produzidos pelas instituições sociais a partir das práticas e valores que elas difundem na sociedade, outras perspectivas analíticas têm sido gestadas no âmbito das teorias que tratam da justiça social.

\section{0 reconhecimento como medida de justiça social}

Pode-se dizer que a busca pela superação da desigualdade social tem sido o grande objetivo das teorias contemporâneas sobre justiça. Nas últimas décadas, a atualização do debate colocou outros paradigmas em cena. Por muito tempo o paradigma da justiça distributiva foi considerado adequado para analisar as reivindicações, fundamentalmente, dos trabalhadores e dos pobres. Nos regimes democráticos de bem-estar desencadearam-se conflitos, sobretudo por recursos, e a discussão polarizou-se no terreno distributivo com apelo a normas universalistas e mantendo à margem outro conjunto de questões relacionadas com a diferença. Entendia-se que as reivindicações de uma distribuição igualitária representavam o ideal de justiça. Entre os principais expoentes dessa corrente encontra-se John Rawls, cujos princípios definidores de justiça encontram-se na origem do atual debate.

Kymlicka (2006:66), referindo-se à teoria de Rawls, destaca que

sua concepção de justiça é composta de uma ideia central: todos os bens primários sociais liberdade e oportunidade, renda e riqueza, e as bases do respeito de si mesmo - devem ser distribuídos igualmente, a menos que a distribuição desigual de qualquer um ou de todos esses bens seja vantajosa para os menos favorecidos. Nessa concepção geral, Rawls vincula a ideia de justiça a uma parcela igual de bens sociais, mas acrescenta uma importante modificação. Tratamos as pessoas como iguais não removendo todas as desigualdades, mas apenas as que trazem desvantagem para alguns.

Sinteticamente, Rawls procura harmonizar os princípios liberais de igualdade jurídica com o objetivo de reduzir as desigualdades sociais, priorizando em sua teoria o princípio dis- 
tributivo. Os anos 1960, porém, registram o surgimento de demandas referentes a questões identitárias, de gênero, culturais, lutas contra as mais variadas formas de discriminação, que passaram a compor o cenário mais amplo na esfera pública. Surgia então um novo campo de conflitos, que serviria de base para se pensar o princípio da igualdade e seu universalismo.

No Brasil, a década de 1970 foi marcada pelo afloramento de uma diversidade de movimentos sociais: "a heterogeneidade constitutiva da estrutura social induziria à reprodução das diversidades no plano das manifestações sociais" (Sader, 1988:197). O reconhecimento passa a chamar atenção, configurando-se em objeto de análise de vários teóricos, como Charles Taylor (2000), Nancy Fraser (2001, 2006, 2008) e Axel Honneth (2003, 2006). Para esses autores, essa categoria vem se transformando em elemento fundamental nos trabalhos que buscam esclarecer o teor dos debates acerca da identidade e da diferença, independentemente do conteúdo, sejam reivindicações territoriais, questões de gênero, discriminação etc. Assim, recorre-se cada vez mais ao termo para revelar as bases normativas das reivindicações políticas.

Todavia, se a categoria reconhecimento é hoje indiscutível, sua relação com a redistribuição carece de um tratamento maior. Atualmente, diante das transformações promovidas pelos processos de globalização, a busca por um patamar de justiça social deve englobar ao menos dois conjuntos de questões: as que se projetam com base nas lutas por redistribuição e as que se originam nas reivindicações por reconhecimento (Fraser e Honneth, 2006).

No plano teórico, o enfrentamento dessas questões tem sido objeto de controvérsias, uma vez que tem mobilizado um contingente expressivo de intelectuais que, com base em orientações díspares, enfrentam o problema da relação entre redistribuição e reconhecimento, "buscando estabelecer uma posição crítica em relação às lutas sociais contemporâneas, teorizar o lugar da cultura no capitalismo e pensar padrões de justiça" (Silva, 2005:4).

O debate que envolve o reconhecimento como elemento fundamental na busca pela igualdade e, consequentemente, por uma sociedade livre de desigualdades sociais pode ser agrupado em dois grandes blocos de trabalhos. De um lado, há os que entendem que a categoria reconhecimento diz respeito à autorrealização (estima). De outro, em contraposição, há os que entendem que o reconhecimento deve ser tematizado como uma questão de justiça. Apresentam-se, pois, a seguir, algumas das formulações teóricas que embasam as duas perspectivas.

Para Charles Taylor (2000), o prestígio adquirido pela categoria reconhecimento nas sociedades contemporâneas deve-se ao vínculo existente entre reconhecimento e identidade, em que a identidade designa algo como a compreensão de quem a pessoa é, de suas características definidoras e fundamentais da condição de seres humanos. Sua tese é que a identidade é moldada, em parte, pelo reconhecimento ou por sua ausência, de tal forma que uma pessoa, ou grupo, pode sofrer danos reais ou uma real distorção, caso a sociedade da qual faz parte lhe devolva um quadro redutor de si mesma(o), desmerecedor ou mesmo desprezível. Assim, o devido reconhecimento não é uma mera cortesia que se deve conceder às pessoas, mas sim uma necessidade humana vital. 
Axel Honneth (2003), adotando um quadro interpretativo próximo ao de Charles Taylor, afirma que, por meio do reconhecimento intersubjetivo, os sujeitos podem garantir a plena realização de suas capacidades e uma autorrelação marcada pela integridade. Em consequência, os sujeitos são forjados em suas interações, e eles só conseguem formar uma autorrelação positiva se forem reconhecidos pelos seus parceiros de interação. Axel Honneth é, sem dúvida, o mais proeminente representante da terceira geração da Escola de Frankfurt. Seu esforço acadêmico tem se concentrado na tarefa de dotar a teoria crítica de uma nova base heurística e epistemológica, fundamentada numa teoria do reconhecimento. Qualquer reconstrução esquemática de seu pensamento, por mais simplificada que seja, não pode deixar de destacar como ele se vincula a essa tradição.

Como herdeiro da teoria crítica, Honneth (2009) identifica um legado intelectual que vai servir de base a suas formulações. Esse legado, acompanhando Madureira (2009), pode ser definido em três recursos presentes nessa tradição. Primeiro, Honneth destaca o caráter patológico da sociedade contemporânea e sua ubiquação, no que ele define como déficit de racionalidade. Junto a essa convicção, encontra-se associado um parâmetro normativo do que seria o patológico e, implicitamente, uma concepção de boa vida ou de possibilidade de autorrealização (do inglês self actualization). Em outras palavras, a tendência de uma pessoa a desenvolver todas as suas possiblidades de crescimento, o desenvolvimento de si mesma. Em segundo lugar, vem a convicção, baseada na relação da teoria com as ciências sociais, de que esse déficit de racionalidade é uma decorrência da forma de organização característica do capitalismo. Por fim, Honneth deriva a ideia de que a crítica às patologias sociais e a possibilidade de superá-las provêm da mesma racionalidade cujo desenvolvimento pleno se encontra bloqueado e se expressa no sofrimento. Sofrimento esse que surge em decorrência de um desejo emancipatório. Esses três pontos servirão de base para os desenvolvimentos posteriores do autor.

Em Luta por reconhecimento: a gramática moral dos conflitos sociais, Honneth parte dos sentimentos de desrespeito e de não reconhecimento, naquilo que eles apontam, ou seja, "seu caráter normativo: a irracionalidade da sociedade moderna capitalista aparecerá no marco de uma teoria com forma própria, nas limitadas garantias de autorrealização pessoal, implícitas em sua própria estrutura social" (Madureira, 2009:20).

Em seus desenvolvimentos teóricos, Honneth busca inspiração na obra de dois autores: Hegel e George Herbert Mead. No conceito de luta por reconhecimento proposto por Hegel, o autor encontra os elementos para desenvolver um conceito de luta moralmente motivada que permite reproduzir a noção de conflito. Hegel defendia, em seus textos de Jena,

a convicção de que resulta de uma luta dos sujeitos pelo reconhecimento recíproco de sua identidade uma pressão intrassocial para o estabelecimento prático e político de instituições garantidoras da liberdade; trata-se da pretensão dos indivíduos ao reconhecimento intersubjetivo de sua identidade, inerente à vida social desde o começo na qualidade de uma tensão moral que volta a impelir para além da medida institucionalizada de progresso social e, desse modo, pouco a pouco a um estado de liberdade comunicativamente vivida, pelo caminho negativo de um conflito a se repetir de maneira gradativa. [Honneth, 2003:29] 
Entretanto, para Honneth, o modelo teórico de luta por reconhecimento proposto por Hegel deve ser retomado na perspectiva de uma teoria social normativa. Essa empreitada apresenta algumas dificuldades, uma vez que as reflexões que embasam o modelo hegeliano devem parte de sua força a pressupostos da razão idealista que não podem mais ser sustentados, sendo necessária uma reatualização de suas formulações. É com essa dificuldade em vista que Honneth recorre à psicologia social de Mead, onde encontra o conceito intersubjetivista de pessoa, apropriado às formulações de Hegel. A obra de George Mead possibilita, ao nosso autor, reatualizar a concepção de luta por reconhecimento de Hegel, com uma concepção do caráter moral dos conflitos sociais que lhe confere um rol central no desenvolvimento moral das sociedades e do conflito, um conceito formal de etnicidade baseado nas condições intersubjetivas da integridade pessoal.

Para Mead, o processo de socialização e as interações são responsáveis pelo desenvolvimento pleno da identidade dos indivíduos, e a luta por reconhecimento é o ponto de referência da evolução moral da sociedade. Dois são os pontos de partida da empreitada de Mead. Inicialmente, ele se apoia em um olhar intersubjetivista, pelo qual o desenvolvimento do self, e consequentemente da identidade, só pode ocorrer mediante processos sociais de experiência e atividade em um indivíduo dado, resultando das "relações do indivíduo com esse processo como um todo, e com os outros indivíduos que se encontram dentro desse processo" (Mead, 2010:167). Desse modo, o self torna-se um objeto para si, ou seja, torna-se para si mesmo sujeito e objeto ao mesmo tempo. Em segundo lugar, Mead investiga a relevância das normas morais nas relações humanas. Para o autor, nas interações sociais ocorrem conflitos entre o eu, a cultura e os outros, por meio dos quais indivíduos e sociedade se desenvolvem moralmente. Em outras palavras, a autorrealização dos sujeitos depende de uma relação de reconhecimento, segundo a qual "todo sujeito pode saber-se confirmado como uma pessoa que se distingue de todas as outras por propriedades e capacidades particulares" (apud Honneth, 2003:149).

Winnicott (apud Honneth, 2003) analisa as interações entre mãe e filho buscando compreender como se constitui o processo pelo qual mãe e filho podem se separar do estado de ser-um para aprenderem a se amar e se conceberem como pessoas autônomas. Para Winnicott, um aprende com o outro a diferenciar-se e se ver como ser independente (mesmo que em certa medida mantenham certo grau de dependência mútua), podendo sobreviver sozinhos, do que advém a possibilidade da autoconfiança.

É com base nesses autores que Honneth (2003) desenvolve uma tipologia formada por três formas distintas de reconhecimento: a) as relações primárias, cujas formas de reconhecimento são o amor e a amizade; b) as relações legais, cujas formas de reconhecimento são as identificadas com os direitos; e c) as comunidades de valor, cuja forma de reconhecimento é a solidariedade. Para cada uma dessas dimensões - amor, direito, solidariedade - existe uma relação prática do sujeito com o self, relações definidas, respectivamente, como autoconfiança básica, autorrespeito e estima social.

Conforme esse esquema teórico, a possibilidade de formação de indivíduos autônomos depende do desenvolvimento dessas três formas de relação com o self. Por outro lado, essas 
formas de relação com o self só podem ser adquiridas mediante o reconhecimento de outros (Silva, 2005). Assim, pode-se dizer que o sujeito deve ter suas qualidades e capacidades reconhecidas e legitimadas pelos outros, de forma que, sentindo-se reconhecido, disponha-se a reconhecer também o outro em suas singularidades.

Por fim, cada uma dessas formas de reconhecimento contém um potencial para o conflito, pois são moralmente motivadas por formas de desrespeito. Os componentes violados por formas de desrespeito são, respectivamente, a integridade física, a integridade social e a dignidade da pessoa. As ideias de Honneth são oportunas em termos de teoria social, pois o autor coloca no centro do debate elementos importantes para a análise da desigualdade social em termos de conflito.

Nesse aspecto, há proximidade entre o trabalho de Honneth e algumas perspectivas desenvolvidas no Brasil, como as teses apresentadas por Vera da Silva Telles. Segundo a autora, é pelo conflito

que os não iguais impõem o seu reconhecimento como indivíduos e interlocutores legítimos, dissolvendo as hierarquias nas quais estavam submissos numa diferença sem equivalência possível. É nele, portanto, que se decifra o enigma dos direitos, enquanto conquistas de reconhecimento e legitimidade, sem o que a cidadania formulada nos termos da lei não se universaliza e não tem como se enraizar nas práticas sociais. [Telles, 2001:30]

Entretanto, os aportes de Honneth ainda suscitam alguns questionamentos. Ao ampliar significativamente a categoria reconhecimento, o autor acaba por criar uma teoria monística, ou seja, uma teoria estruturada com base em um conceito único capaz de englobar todas as dimensões da vida social. Em sua versão de uma teoria do reconhecimento diferenciada, Honneth esclarece serem os sentimentos de injustiça e de desrespeito o combustível que alimenta grande parte dos conflitos vivenciados na sociedade contemporânea (Honneth, 2006:91). Assim, deve-se buscar na base dessas ofensas moralmente localizadas o fio condutor para interpretar a ação moralmente motivada, do mesmo modo que ele deve servir de guia para o equacionamento das situações de injustiça.

De um lado, Honneth (2003) tem o mérito de apontar que o reconhecimento, como autorreconhecimento (estima), é fundamental para a construção do sujeito da ação na luta social, o que é particularmente evidente em alguns grupos ou movimentos sociais no Brasil. De outro, o autor não apresenta uma explicação acerca do contrário. Ou seja, não explica quando os sentimentos de injustiça ou desrespeito funcionam não mais como combustível para a ação reivindicadora de justiça social, mas como inibidores da ação.

Em muitas situações, indivíduos ou grupos submetidos a um sentimento de humilhação pública ou de inferioridade acabam por assimilar essa visão negativa, autointerpretandose como não capazes ou não merecedores de determinadas considerações sociais. Paugam (2003), em uma pesquisa com pessoas expostas a estigmas em decorrência do desemprego, conclui que elas acabam, em última instância, buscando o isolamento social e não a mobili- 
zação. Nesses casos, o sentimento de vergonha social fala mais alto do que a capacidade de mobilização e superação das adversidades.

Outra dificuldade a enfrentar é a maneira como Honneth (2003) inclui a luta pelo reconhecimento na tradição crítica. Avritzer (2007) pondera que a visão de Honneth não possibilita compreender a maneira como os movimentos sociais postulam o reconhecimento como luta política. Para Avritzer, o problema diz respeito essencialmente a duas questões. Em primeiro lugar, para o autor, Honneth reduz cada uma das formas de desrespeito à falta de autoestima do próprio self. Como o self é uma categoria do indivíduo, o problema reside no fato de que as formas de reconhecimento mais vigorosas, notadamente gênero e raça, encontram-se vinculadas às formas de ação coletiva, como o movimento feminista e os movimentos raciais. Em segundo lugar, há o problema do status heurístico diferenciado das três categorias apontadas por Honneth. Em sua tipologia, as três formas de reconhecimento representam momentos de equacionamento das injustiças advindas das três formas de desrespeito. O problema com a homologia das três categorias é que o amor é uma categoria do self,

ao passo que nem os direitos nem a solidariedade podem ser considerados categorias do self, mesmo quando esse é pensado nos termos de um reconhecimento do outro. Sendo assim, o equívoco que Honneth comete de saída é categorizar o reconhecimento nos termos do self (Honneth, 1992:190-191), sem perceber que a luta pelo reconhecimento assume dimensões inerentemente coletivas e está ligada à maneira como movimentos sociais colocam a reivindicação de reconhecimento em público. [Avritzer, 2007:7]

Sem dúvida, a visão de Honneth (2003) acaba por retirar da categoria reconhecimento grande parte do seu potencial. O reconhecimento, como destaca Pinto (2008), é um conceito polissêmico e reduzi-lo à autorrealização exclui tanto seu valor heurístico para a teoria social como sua potencialidade na luta por justiça. A redução do reconhecimento à autorrealização permite a Honneth, no mesmo movimento, reduzir a redistribuição ao reconhecimento.

$\mathrm{Na}$ difícil tarefa de se pensar sobre as injustiças econômicas, novas propostas teóricas têm sido formuladas com base em outras leituras relativas às dimensões que tipificam o conceito de justiça social.

\section{A tridimensionalidade da justiça social: a perspectiva de Nancy Fraser}

Parece que as reivindicações de justiça social têm se dividido, cada vez mais, em dois tipos. O primeiro, mais conhecido, relaciona-se com as reivindicações redistributivas, que pretendem uma distribuição mais justa dos recursos e da riqueza. O segundo tipo refere-se à política de reconhecimento e seu objetivo mais aparente é um mundo que aceite a diferença. Nesse cenário, Fraser (2006) aponta a possibilidade de desenvolvimento de um novo paradigma de justiça social que integre as duas reivindicações, em vez de separá-las, uma vez que esses conjuntos de reivindicações aparecem dissociados tanto na prática como intelectualmente. 
Em alguns casos, entretanto, essa dissociação constitui-se em polarização. Observa-se que alguns proponentes da redistribuição rechaçam de pronto a política do reconhecimento, considerando as reivindicações pelo reconhecimento da diferença uma falsa consciência, verdadeiros óbices à consecução da justiça social. Do mesmo modo, os defensores das políticas de reconhecimento desdenham as políticas de redistribuição, citam o fracasso do igualitarismo em garantir a justiça social às mulheres e às minorias e consideram a política distributiva um materialismo fora de moda, incapaz de articular ou questionar as novas experiências de injustiça (Fraser, 2006).

Fraser (2001) opõe-se contra essa bipolarização de reivindicações. Em "Da redistribuição ao reconhecimento? Dilemas da justiça na era pós-socialista”, a autora faz um diagnóstico dos conflitos políticos do final do século XX, ressaltando que a mudança paradigmática na agenda dos movimentos sociais conduziu a um deslocamento das demandas por redistribuição para a emergência de lutas por reconhecimento. Os discursos por justiça social, que outrora centravam-se na distribuição, agora apresentam-se cada vez mais divididos entre reivindicações de redistribuição e reivindicações por reconhecimento.

Essa crítica foi retomada por outros autores, como Bauman (2005:44):

A guerra por justiça social foi reduzida a um excesso de batalhas por reconhecimento. "Reconhecimento" pode ser aquilo que mais faça falta a um ou outro grupo dos bem-sucedidos — a única coisa que parece estar faltando no inventário rapidamente preenchido dos fatores de felicidade. Mas, para uma parcela ampla e em rápido crescimento da humanidade, trata-se de uma ideia obscura que assim continuará sendo enquanto o dinheiro for evitado enquanto tema de conversa.

Partindo de uma definição em que a justiça social engloba ambas as reivindicações, Nancy Fraser (2006) elabora uma tipologia dos movimentos sociais que ajuda a ilustrar sua tese da irredutibilidade entre as duas categorias. Como paradigmas populares, tanto a redistribuição como o reconhecimento associam-se aos movimentos sociais concretos. A política de redistribuição identifica-se com as políticas de classe, de um lado, ao passo que a política de reconhecimento se assimila às políticas de identidade e com as lutas de gênero, sexualidade, nacionalidade, raça etc. Entretanto, redistribuição e reconhecimento diferem pelo menos em quatro aspectos.

Em primeiro lugar, os dois paradigmas assumem pontos de vista distintos. A concepção paradigmática da redistribuição concentra-se nas injustiças definidas como socioeconômicas e atribui que suas ocorrências advêm da estrutura econômica da sociedade. Já o paradigma do reconhecimento centra suas atenções nas injustiças caracterizadas como culturais, que supõem arraigadas em padrões sociais de representação, interpretação e comunicação.

Em segundo lugar, os dois paradigmas propõem diferentes tipos de soluções para as injustiças. A redistribuição busca o equacionamento das injustiças em alguma forma de reestruturação econômica, e o paradigma do reconhecimento propõe uma mudança de âmbito cultural e simbólico. No entanto, há outras diferenças. Ambos os paradigmas divergem em relação às coletividades que sofrem injustiças. De um lado, os proponentes do paradigma da 
redistribuição especificam que os sujeitos que sofrem injustiças são as coletividades similares às classes que se definem economicamente por uma relação com o mercado e os meios de produção. De outro lado, o paradigma do reconhecimento entende que os sujeitos vítimas de injustiça se encontram submetidos a padrões institucionalizados de valor cultural e se assemelham aos grupos de status weberiano. Definidas pelas relações de reconhecimento, distinguem-se pelo respeito, estima e prestígio que desfrutam em relação a outros grupos da sociedade, abarcam outros casos como os grupos estigmatizados institucionalmente, os grupos racializados marcados como diferentes e inferiores, entre outros, que sofrem formas variadas de desrespeito.

Por fim, em relação ao quarto aspecto, os paradigmas apresentam ideias distintas acerca das diferenças de grupo. Quanto ao paradigma da redistribuição, não se trata de conceber os diferenciais como algo intrínseco aos grupos, mas como uma economia política injusta socialmente estruturada. Já o paradigma do reconhecimento trata as diferenças de duas maneiras possíveis. Em uma versão, são variações culturais transformadas em hierarquias de valores mediante esquemas interpretativos injustos. Em outra, as diferenças de grupos não existem antes de sua transvalorização hierárquica e são contemporâneas de si mesmas (Fraser, 2006).

Diante dessas observações, e contra a visão de que a redistribuição e o reconhecimento são alternativas mutuamente excludentes, Fraser (2001, 2006, 2008) apregoa que se trata de uma falsa antítese.

Sua tipologia consiste, inicialmente, na formulação de um modelo bidimensional construído com base em tipos puros. Pode-se imaginar um espectro conceitual de tipos diferentes de coletividades sociais, nos quais em um extremo estão os modos de coletividade que se ajustam aos modelos redistributivos de justiça e, em outro, estão os modos de coletividades relacionados com os modelos de reconhecimento. Esse procedimento permite à autora classificar os movimentos sociais segundo suas demandas na relação redistribuição/reconhecimento.

Quanto ao aspecto da redistribuição, Fraser estabelece um tipo ideal de coletividade cuja existência esteja ligada à economia política. Desse modo, “a raiz da injustiça será a má distribuição socioeconômica e qualquer injustiça cultural adicional derivará em última instância da raiz econômica" (Fraser, 2001:254). O remédio para reparar essa injustiça é a redistribuição político-econômica, em oposição ao reconhecimento cultural. Nesse quadro, considerado para fins heurísticos, a classe operária explorada assume o modelo de tipo ideal.

Assim, a diferenciação de classe enraíza-se na estrutura econômica da sociedade capitalista. A classe trabalhadora constitui-se como um conjunto de pessoas que necessitam vender sua força de trabalho em condições que permitem à classe capitalista apropriar-se da mais-valia para seu benefício privado. A injustiça fundamental, portanto, é a exploração: uma forma especialmente profunda de má distribuição na qual as próprias energias do proletariado se voltam contra ele, usurpadas para sustentar um sistema que beneficia outros. Mesmo sabendo que os proletários sofrem graves injustiças culturais, elas derivam da ordem econômica. Entretanto, longe de vincular-se diretamente a uma ordem autônoma injusta de categorias, as mesmas derivam da estrutura econômica, onde proliferam as ideologias da inferioridade de classe para justificar a exploração (Fraser, 2001, 2006). 
Seguindo os mesmos critérios, pode-se colocar na outra ponta do espectro um tipo ideal de coletividade que se ajuste ao modelo de reconhecimento da justiça. Uma coletividade desse tipo deve estar totalmente enraizada na cultura e não na economia política. Cabe destacar que essas coletividades são diferenciadas por padrões sociais dominantes e não pela divisão social do trabalho. Desse modo, todas as injustiças estruturais que lhes atribuam derivam de padrões institucionalizados de valor de uma sociedade. O núcleo dessas injustiças é o reconhecimento incorreto, ao passo que as injustiças econômicas que a elas se adicionam procedem, em última instância, da ordem de status.

Para sanar esses tipos de injustiça, o que se requer é o reconhecimento e não a redistribuição. Um exemplo de coletividades que se aproxima desse tipo ideal são os grupos que enfrentam as diferenças sexuais, conforme a concepção weberiana de status. Nesse sentido, a divisão social entre heterossexuais e homossexuais distribui-se por toda a estrutura de classe na sociedade capitalista, não ocupa uma posição característica na divisão do trabalho e não constitui uma classe explorada.

Dessa forma,

La división se enraíza, mas bien, en el orden de estatus de la sociedad, pues los patrones institucionalizados de valor cultural interpretan la heterosexualidad como natural y normativa, y la homosexualidad como perversa y depreciable. Esos patrones heteronormativos de valor, institucionalizados de forma generalizada, estructuran grandes franjas de interaccion social. Expresamente codificadas en muchas áreas del derecho (incluyendo el derecho de familia y el derecho penal), informan las interpretaciones jurídicas de la familia, la intimidad, la privacidad y la igualdad. También están muy arraigados en muchas áreas de la política de gobiernos (incluyendo las políticas de inmigración, naturalización y asilo) y en las prácticas profesionales estándar (incluyendo la medicina y la psicoterapia). Los patrones heteronormativos de valor también invaden la cultura popular y la interacción cotidiana. [Fraser, 2006:27]

Portanto, quando se lida com coletividades que se aproximam da classe operária explorada, os remédios são redistributivos, e com coletividades que se aproximam do tipo ideal de sexualidade menosprezada, as injustiças requerem ações no âmbito do reconhecimento. No primeiro caso, a lógica consiste em homogeneizar os grupos; no segundo, a lógica é valorizar a peculiaridade do grupo, reconhecendo sua especificidade. Em outras palavras, os remédios redistributivos e de reconhecimento indicam lógicas opostas.

As questões apresentam-se de uma forma mais fácil de identificar e postular equacionamentos nos extremos desse espectro conceitual. Do mesmo modo, tornam-se mais complexas quando se lida com grupos que se encontram no meio desse modelo conceitual. Nessa posição, há uma forma híbrida que relaciona ambas as características, aspectos da classe explorada com elementos da sexualidade desprezada, isto é, são grupos que demandam ao mesmo tempo redistribuição e reconhecimento. A esses grupos Fraser (2006) chama de coletividades ambivalentes, por se caracterizarem por uma bidimensionalidade de injustiças, arraigadas simultaneamente na estrutura econômica e na ordem de status. Nenhuma dessas injustiças 
caracteriza-se como consequência uma da outra. Ao contrário, ambas são primárias e co-originais (Fraser, 2001, 2006).

As coletividades formadas por identificação de gênero e raça, por exemplo, são bidimensionais. Na perspectiva da autora, embora cada uma tenha peculiaridades não compartilhadas pela outra, ambas englobam dimensões político-econômicas e culturais-valorativas. Como sofrem injustiças de ordem socioeconômica e de não reconhecimento, simultaneamente, nem remédios redistributivos, nem remédios de reconhecimento são suficientes isoladamente. Coletividades ambivalentes necessitam de ambos.

Em trabalho posterior, Fraser (2008) acrescentou uma terceira dimensão ao debate: a dimensão política. Na sua perspectiva, o político é entendido em um sentido mais específico e constitutivo, que remete à natureza da jurisdição do Estado e às regras de decisão com que se estrutura a confrontação. Nesse entendimento, o político é o cenário no qual se desenvolvem as lutas por distribuição e reconhecimento. Ao estabelecer os critérios de pertencimento e ao determinar quem conta como membro, a dimensão política da justiça especifica o alcance das outras dimensões. Ela informa quem faz parte ou não do grupo dos que têm direito a uma justa redistribuição ou ao reconhecimento mútuo.

Ao determinar as regras de decisão, a dimensão política, do mesmo modo, determina os procedimentos para representar e resolver os conflitos nas outras dimensões. Em síntese, a dimensão política não apenas indica quem tem o direito a reivindicar redistribuição e reconhecimento, como estabelece e avalia essas reivindicações (Fraser, 2008).

Tendo como pano de fundo a questão do pertencimento e procedimentos, Fraser (2008) destaca:

a dimensión política de la justicia se interesa sobre todo por la representación. En un primer nivel, el que atañe al aspecto de establecimiento de límites de lo político, la representación es asunto de pertencia social. De lo que se discute aquí es de la inclusión en o de la exclusión de la comunidad de aquellos que tiene derecho a dirirse mutuamente reivindicaciones de justicia. En otro nível, el relativo al aspecto de las regras de decisión, la representación se interesa por los procedimientos que estructuran los processos públicos de confrontación. Aquí, lo que se cuestiona son las condiciones en las que los incluidos en la comunidad política airean sus reividicaciones y arbritan sus disputas. En ambos niveles puede surgir la cuestión de si y hasta qué punto son justas las relaciones de representación. [Fraser, 2008:42]

Se a representação é a condição que define o político como dimensão da justiça, então a injustiça política característica é a representação falida - que, segundo Fraser (2008), ocorre quando os limites políticos e as regras de decisão vigentes negam a determinados sujeitos a possibilidade de participar, em paridade com outros, nos processos de interação social. Na prática, essa forma de injustiça não ocorre desvinculada, mas imbricada com as demais.

Com a entrada em cena dessa terceira dimensão, a autora busca superar um dos limites do seu modelo anterior (bidimensional), qual seja: a apropriação do discurso. Conforme observa Pinto (2008), parece haver nas formulações de Fraser um elemento faltante entre o reconhecimento e a redistribuição. 
O elo perdido parece ser o processo de construção de discurso ou a apropriação de elementos discursivos (que Fraser chama de paradigmas populares) por parte daqueles excluídos sociais, para que no espaço público eles possam constituir-se como promotores da ação social a partir da sua própria construção como agente, concomitante às demandas e ao aparecimento de espaços e possibilidades políticas de reconhecimento. [Pinto, 2008:48]

Os recursos mobilizados e articulados na ação discursiva servem como bússolas para direcionar as ações e fornecem subsídios para se pensar e interpretar a ação na prática.

O objetivo de Fraser (2001, 2002) é mostrar que tanto as injustiças formadoras das desigualdades econômicas como as do não reconhecimento são impedimentos à participação plena na esfera pública. Nesse caso, o problema reside em encontrar soluções que contemplem ambos os níveis da justiça, de maneira que não haja uma substituição de um nível por outro. Ou seja, sem o estabelecimento da igualdade em seus vários níveis, não há uma participação de fato entre iguais. O reconhecimento torna-se, portanto, "um meio de superar as formas de subordinação que são institucionalizadas, ao invés de, simplesmente, valorizar um grupo excluído" (Ogando e Assis, 2006:2).

Fraser (2001, 2006), então, postula a formulação de um princípio normativo que inclua ambas as reivindicações, sem reduzir uma à outra. Propõe o princípio da paridade de participação, segundo o qual a justiça requer arranjos sociais que permitam a todos os membros da sociedade interagir como pares. São necessárias, contudo, duas condições para que a paridade participativa seja possível. Primeiro, deve haver uma distribuição de recursos materiais que garanta a independência e a voz dos participantes. Essa condição impede a existência de formas e níveis de dependência e desigualdade econômicas que constituem obstáculos à paridade de participação. Segundo, a paridade participativa requer que os padrões institucionalizados de valor cultural exprimam igual respeito por todos os participantes e garantam iguais oportunidades com o objetivo de alcançar a consideração social.

\section{Considerações ao estudo da justiça social no Brasil}

No Brasil, a desigualdade e a discriminação de gênero e raça são fenômenos que atingem não apenas grupos específicos da sociedade, mas a maioria dela. Segundo dados da Organização Internacional do Trabalho (OIT) (2006), as mulheres e a população negra representam, respectivamente, $42 \%$ e 44,5\% da população economicamente ativa (PEA) brasileira. Somadas, correspondem a 55 milhões de pessoas ou a 68\% da PEA no Brasil, ou seja, uma ampla maioria: 36 milhões de negros de ambos os sexos e quase 19 milhões de mulheres brancas. Acrescente-se a esse quadro uma infinidade de outras desigualdades de ordem material e simbólica.

Nos últimos anos tem havido um esforço do governo brasileiro em implantar e consolidar políticas que objetivam reduzir as desigualdades sociais no país. A repercussão dessas ações no âmbito político fez-se sentir por ocasião da reeleição de Luiz Inácio Lula da Silva à presidência. Seu primeiro mandato suscitou entre os eleitores e observadores internacionais 
muitas expectativas no tocante à implementação de políticas de redistribuição de renda e justiça social (Krischke, 2003).

À parte o debate realizado sobre o plano macroeconômico (por ocasião da campanha eleitoral para a reeleição), assistiu-se a uma ampla discussão das políticas sociais que chegou, em certo momento, a transformar-se em estratégia de campanha da oposição, que admitia a continuidade e ampliação das políticas sociais e programas, como o Bolsa Família.

Contudo, em alguns setores da sociedade, não raro ouviram-se contra tais políticas frases como "Não vou votar no Lula porque ele está dando dinheiro para vagabundos" ou "Desse jeito eles nunca vão ir trabalhar, pois ganham sem fazer nada". Tal embate, quando teorizado no âmbito da justiça social e da consolidação da democracia, indica que, mesmo diante da aprovação das ações governamentais nas urnas, verifica-se a existência de conflitos acerca das demandas por justiça social. Surge uma série de questionamentos, conduzindo ao centro do debate um conjunto de imprecisões referentes a quem tem legitimidade para reivindicar justiça. Em outras palavras, quais são os sujeitos ou grupos que devem ser objeto das ações em prol da justiça social? O que se deve distribuir para garantir um patamar de justiça social? Quem deve ser o agente operacionalizador das ações para justiça social e como? Ou, para usar os termos de Fraser (2006), quem deve ministrar os remédios, a sociedade civil, o Estado, ou ambos?

É importante esclarecer que, embora o Bolsa Família seja um programa de governo, encontra-se fortemente institucionalizado. Segundo Di Giovanni (2010:6),

Em geral, diz-se que as políticas de Estado são aquelas que conseguem ultrapassar os períodos de um governo. Ou seja, políticas públicas são políticas de Estado ou políticas de governo. A diferença entre aquilo que é política de Estado e o que é política de governo é a maneira como elas são institucionalizadas. Se elas são fortemente institucionalizadas em uma sociedade, torna-se difícil mudá-las. Não adianta trocar o governo. Um exemplo disso é o Bolsa Família. Dificilmente, se houver um governo diferente do atual, ele vai mexer nesse programa.

O prognóstico apresentado por Di Giovanni tem se confirmado nas ações da posição que em 2013, por intermédio do senador da República e presidente do Partido da Social Democracia Brasileira (PSDB) Aécio Neves, propôs transformar o Bolsa Família em uma política de Estado.

Enfim, é preciso aprofundar o debate acerca da singularidade da desigualdade social no Brasil, visto que o conflito social moderno "diz respeito ao ataque às desigualdades que restringem a participação cívica integral, por meios políticos, econômicos ou sociais, e ao estabelecimento de prerrogativas que constituam um status rico e integral de cidadania" (Dahrendorf, 1992:52). Entende-se, portanto, que a desigualdade é consequência de uma série de desajustes e tem uma origem multidimensional.

Com tais considerações, e retomando o debate sobre as teorias abordadas, observa-se que tanto o pensamento de Axel Honneth como o de Nancy Fraser, embora com perspectivas diferentes, não se configuram como teorias antagônicas. Em pesquisas aplicadas ao caso brasileiro, Celi Pinto tem insistido na importância de concebê-las de maneira complementar: 
para a avaliação de situações brasileiras, abandonar uma proposta em favor de outra empobreceria as qualidades heurísticas e normativas, que podem ser encontradas na combinação das duas. Tal procedimento é fundamental no meu entendimento, pois possibilita a não redução da distribuição ao reconhecimento e, ao mesmo tempo, não limita o reconhecimento ao autorreconhecimento (autoestima) ou à política de status. Esta abertura permite o entendimento da complexidade de cenários em embates, tanto no interior da sociedade, como nas políticas públicas, suas aplicações e limites. [Pinto, 2008:57]

Tal perspectiva encontra consonância na visão de Kymlicka (2006). O autor entende que, em relação à pluralidade de valores e objetos existentes nas sociedades contemporâneas, deve-se rejeitar o monismo teórico e aceitar que uma teoria da justiça bem-sucedida deve acolher peças e pedaços da maioria das teorias existentes. Valendo-se desses debates teóricos, propõe-se deslindar os elementos que operam como agentes na manutenção da desigualdade social. De maneira análoga, são importantes as intuições de Caillé (2008), para quem o debate sobre reconhecimento e redistribuição ganharia novo alcance se acrescido de uma teoria do valor.

A proposição de Caillé nos remete, entre outras coisas, a algumas observações realizadas no início deste trabalho sobre o fato de que, nas sociedades, os grupos e/ou sujeitos valem-se da concepção e utilização dos bens para a instituição de hierarquias de controle ou subordinação de outros grupos e/ou sujeitos. Por consequência, a discussão é remetida ao âmbito da divisão social do trabalho, percebendo-se, por outro lado, que as mudanças da estrutura social e das formas de produção trouxeram à tona "outras figuras da desigualdade do que as vinculadas ao modelo clássico da sociedade industrial. Mais que as desigualdades propriamente ditas, é a fragmentação do mercado de emprego que caracteriza os últimos anos" (Dubet, 2003:34).

O autor continua:

A segmentação do mercado de trabalho não se opera unicamente em função de necessidades econômicas, ela ativa e exacerba diferenciações sociais em função do sexo, da idade, do capital educacional, da origem étnica [...] quanto ao desemprego, ele constitui ainda a mais flagrante das desigualdades atingindo grupos sociais tipificados: os jovens, os menos qualificados, os mais idosos, as mulheres, os imigrados. [Dubet, 2003:35]

Seguindo essa linha, observa-se que a distribuição do trabalho envolve bem mais do que questões econômicas - a realização pessoal, o prestígio, o status, o poder, a dignidade pessoal e outras recompensas sociais. O trabalho, para além da função social e/ou de sua necessidade, determina o lugar social e político fundamental e surge como precondição de outros mais. Ou seja, o local de trabalho é o espaço "onde o status social costuma ser definido, onde a vida continua a ser garantida e os direitos de respeito e direito continuam a ser obtidos ou perdidos" (Bauman, 2005:36). Nessa perspectiva, Heller (1998:186) destaca que "na sociedade moderna a função que exercemos na divisão do trabalho determina nossa posição nos padrões de estratificação". 
Por fim, embora se reconheça a necessidade de se considerarem os fenômenos que atuam como construtores dos sujeitos da ação na luta social, esta análise foca-se em outro momento do processo de busca por justiça social e, portanto, os sentimentos morais (como a injustiça, por exemplo) serão considerados, inicialmente, apenas de forma subsidiária. O interesse, aqui, está em averiguar circunstâncias que se manifestam em um momento posterior ao da formação do sujeito da ação na luta, ou seja, de sua capacidade de agência. Esse campo de análise situa-se no contexto de ironia histórica apontado por Lavalle (2003), em que se materializam sérias restrições à expansão da cidadania, fundamentalmente no que diz respeito à capacidade de o Estado universalizar benefícios. Configura-se, assim, um panorama em que as demandas por reconhecimento encontram-se abertas, porém sem equidade.

No Brasil, as medidas adotadas nas últimas décadas como mecanismos de superação da pobreza foram intensificadas pelos efeitos da crise econômica e seguiram o modelo autoritário burocrático, de caráter emergencial, típico das políticas sociais realizadas historicamente no país, sempre pontuais e fragmentadas. Como afirma Sposati (2003:23), "Ao contrário de caminhar na direção da consolidação de direito, a modalidade que irá conformar as políticas sociais brasileiras será primordialmente o caráter assistencial".

No campo da relação capital e trabalho, entendido a partir das divisões de classes, já na década de 1930 surgia um cenário de intensa exploração da classe trabalhadora e, ao mesmo tempo, de reivindicações de direitos sociais básicos. Segundo a Fundação de Economia e Estatística (FEE, 1983), no período de 1930 a 1937 observava-se certa agitação política, com o aparecimento de novas forças sociais colocando em xeque o modelo de acumulação do capital, o que demandou uma "[...] nova articulação de economia e um rearranjo político nas relações entre as classes sociais. Houve uma ampliação do poder e das funções do Estado" (FEE, 1983:33). O Estado assumia uma orientação ratificadora da industrialização e de um projeto modernizador, logo era necessário intervir nas relações entre trabalho e capital no intuito de legitimar e garantir as bases do projeto hegemônico do grande capital.

Nesse período de maior intervenção do Estado na sociedade, além da centralização do poder no governo federal e da redução da autonomia dos estados, facultava ao governo federal, cada vez mais, se adequar às exigências do processo de industrialização. Foi um momento de inovações institucionais, com a criação e reorganização de órgãos para a formulação de medidas que estimulassem a indústria nacional e respondessem aos novos interesses que surgiam no cenário político. As bases da regulamentação do trabalho foram institucionalizadas como ponto estratégico do governo. Registra-se a criação do Ministério do Trabalho, Indústria e Comércio, com a intenção de "subordinar o fator trabalho às novas necessidades engendradas pelo processo de industrialização em curso" (FEE, 1983:22).

O histórico da questão social brasileira remete, portanto, ao pauperismo e às lutas trabalhistas originadas pela acumulação e apropriação desigual da riqueza gerada socialmente. Assim, a questão social é uma categoria que tem sua especificidade definida no âmbito do modelo capitalista de produção, em que as expressões e manifestação se dão em torno da exploração do trabalho, da pobreza, da cidadania limitada, das situações de risco e vulnerabilidade social, e do acentuado quadro de desigualdade que se ampliava. 
A questão social não é senão as expressões do processo de formação e desenvolvimento da classe operária e de seu ingresso no cenário político da sociedade, exigindo seu reconhecimento como classe por parte do empresariado e do Estado. É a manifestação, no cotidiano da vida social, da contradição entre o proletariado e a burguesia, a qual passa a exigir outros tipos de intervenção mais além da caridade e repressão. [Iamamoto e Carvalho, 2008:77]

Para Castel (1998), a questão social é, sobretudo, uma aporia fundamental sobre a qual uma sociedade vivencia fraturas sociais. É posta como um desafio que interroga e põe em questão a capacidade de uma sociedade existir como um conjunto ligado por relações de interdependência, onde o processo de concentração de riquezas e de poder implica o aumento da pobreza, com expressões dramáticas. A questão social, assim, é calcada na desigualdade e injustiça estruturais. A compreensão de Telles (1996) corrobora esse entendimento:

[...] a questão social é a aporia das sociedades modernas que põe em foco a disjunção, sempre renovada, entre a lógica do mercado e a dinâmica societária, entre a exigência ética dos direitos e os imperativos de eficácia da economia, entre a ordem legal que promete igualdade e a realidade das desigualdades e exclusões tramada na dinâmica das relações de poder e dominação. [Telles, 1996:85]

Castel (2005) distingue dois tipos de proteção a esse conjunto de desigualdades e injustiças: a proteção civil, que diz respeito aos bens e liberdades às pessoas e um Estado de direito; e a proteção social, que de certa forma tem o papel de dar cobertura às pessoas que vivenciam riscos e vulnerabilidades diante de circunstâncias imprevisíveis da vida humana. "[...] os sentimentos de insegurança [...] estão relacionadas com os tipos de proteção que uma sociedade garante, ou não garante, de maneira adequada" (Castel, 2005:9). Ganha relevo aqui a necessidade de se assegurar uma seguridade social às pessoas no âmbito das políticas públicas garantidoras de direitos como previdência social, assistência social, saúde, educação, segurança alimentar e o acesso aos demais serviços e bens públicos.

\section{Considerações finais}

A Constituição Federal de 1988 anunciou para o Brasil um novo tempo — o de um Estado democrático reconhecedor de direitos civis, políticos, econômicos, sociais e culturais. Alcançava-se um outro patamar de cidadania, comparável à concepção clássica de Marshall (1967): direitos civis, políticos e sociais. A crítica ao caráter excludente da política social vigente até então encontrava, enfim, seu reconhecimento (Ipea, 2009).

Entretanto, no que diz respeito ao mundo do trabalho, o período encerra controvérsias. Se, de um lado, a Carta de 1988 consolidou direitos sociais, de outro, ao longo dos 20 anos seguintes, ocorreram muitos embates envolvendo tentativas de reforma trabalhista. Apesar de certa resistência, houve um movimento expressivo de flexibilização do trabalho, centrado em 
mudanças na legislação infraconstitucional e, até mesmo, em entendimentos jurisprudenciais e administrativos. Em paralelo, o contexto do mercado de trabalho favoreceu a proliferação de formas precárias de trabalho, em detrimento do assalariamento regular.

A ampliação dos espaços de diálogo entre o Estado - ator central no fomento de ações que possam equacionar a desigualdade social — e a sociedade civil tem despertado entusiasmo. Tem-se observado um importante avanço na adoção de modelos de formulação, implementação e gestão de políticas públicas apoiadas em ações compartilhadas, em que a paridade participativa e o reconhecimento social passam a ser fundamentais ao sucesso dessas políticas. A percepção dos gestores de políticas públicas sobre a importância dessas ações é conditio sine qua non para o alcance de um patamar elevado de justiça social em nosso país.

\section{Referências}

AVRITZER, Leonardo. Do reconhecimento do self a uma política institucional de reconhecimento: uma abordagem da polêmica entre Axel Honneth e Nancy Fraser. In: ENCONTRO ANUAL DA ANPOCS, 31., 26-31 out. 2007, Caxambu. Anais... Anpocs, 2007.

BAUMAN, Zygmunt. Identidade: entrevista a Benedetto Vecchi. Rio de Janeiro: Jorge Zahar, 2005.

CAILLÉ, Alain. Reconhecimento e sociologia. Revista Brasileira de Ciências Sociais, São Paulo, v. 23, n. 66, p. 151-210, fev. 2008. Disponível em: <www.scielo.br/pdf/rbcsoc/v23n66/10.pdf>. Acesso em: 16 mar. 2010.

CAMPBELL, Tom D. Justiça. In: OUTTHWAITE, William; BOTTOMORE, Tom (Org.). Dicionário do pensamento social do séc. XX. Rio de Janeiro: Jorge Zahar, 1996. p. 406-407.

CASTEL, Robert. A insegurança social: o que é ser protegido? Petrópolis: Vozes, 2005.

CASTEL, Robert. As metamorfoses da questão social: uma crônica do salário. Petrópolis: Vozes, 1998.

DAHRENDORF, Ralf. O conflito social moderno: um ensaio sobre a política da liberdade. Rio de Janeiro; São Paulo: Jorge Zahar; Edusp, 1992.

DI GIOVANNI, Geraldo. Entrevista: o que são políticas públicas. CRP-RJ - Jornal do Conselho Regional de Psicologia, v. 7, n. 27, p. 1-3, mar./abr. 2010. Disponível em: <www.crprj.org.br/publicacoes/ jornal/jornal27-geraldodigiovanni.pdf>. Acesso em: 12 maio 2015.

DUBET, François. Desigualdades multiplicadas. Ijuí: Unijuí, 2003.

FEE. Fundação de Economia e Estatística. A política social brasileira 1930-64: a evolução institucional no Brasil e no Rio Grande do Sul. 2. impr. Porto Alegre: Fundação de Economia e Estatística, 1983.

FRASER, Nancy. A justiça social na globalização: redistribuição, reconhecimento e participação. Revista Crítica de Ciências Sociais, Coimbra, n. 63, p. 7-20, 2002. Disponível em: <http://rccs.revues. org/1250>. Acesso em: 25 out. 2006.

FRASER, Nancy. Da redistribuição ao reconhecimento? Dilemas da justiça na era pós-socialista. In: 
SOUZA, Jessé (Org.). Democracia hoje: novos desafios para a teoria democrática contemporânea. Brasília: Editora UnB, 2001. p. 245-282.

FRASER, Nancy. Escalas de justicia. Barcelona: Heder, 2008.

FRASER, Nancy. La justicia social en la era de la política de la identidad: redistribución, reconocimiento y participación. In: FRASER, Nancy; HONNETH, Axel. ¿Redistribución o reconocimiento? Madri: Morata, 2006. p. 17-88.

FRASER, Nancy; HONNETH, Axel. ¿Redistribución o reconocimiento? Madri: Morata, 2006.

HELLER, Agnes. Além da justiça. Rio de Janeiro: Civilização Brasileira, 1998.

HELLER, Agnes; FEHÉR, Ferenc. A condição política pós-moderna. Rio de Janeiro: Civilização Brasileira, 1998.

HONNETH, Axel. Crítica del agravio moral: patologías de la sociedad contemporánea. Buenos Aires: Fondo de Cultura Económica; Universidad Autónoma Metropolitana, 2009.

HONNETH, Axel. Luta por reconhecimento: a gramática moral dos conflitos sociais. São Paulo: Editora 34, 2003.

HONNETH, Axel. Redistribución como reconocimiento: respuesta a Nancy Fraser. In: FRASER, Nancy; HONNETH, Axel. ¿Redistribución o reconocimiento? Madri: Morata, 2006. p. 89-148.

IAMAMOTO, Marilda; CARVALHO, Raul. Relações sociais e o serviço social no Brasil. São Paulo: Cortez, 2008.

IPEA. Instituto de Pesquisa Econômica Aplicada. Políticas sociais: acompanhamento e análise Constituição vinte anos depois. Brasília: Ipea, 2009.

KLEY, Roland. Justiça. In: ENDERLE, Georges et al. (Org.). Dicionário de ética econômica. São Leopoldo: Unisinos, 1997. p. 117-119.

KRISCHKE, Paulo. Governo Lula: políticas de reconhecimento e de redistribuição. Cadernos de Pesquisa Interdisciplinar em Ciências Humanas, Florianópolis, v. 4, n. 47, p. 1-13, out. 2003. Disponível em: <https://periodicos.ufsc.br/index.php/cadernosdepesquisa/article/view/2184/4430>. Acesso em: 14 jan. 2007.

KYMLICKA, Will. Filosofia política contemporânea. São Paulo: Martins Fontes, 2006.

LAVALLE, Adrian Gurza. Cidadania, igualdade e diferença. Lua Nova, São Paulo, n. 59, p. 75-93, 2003. Disponível em: <www.scielo.br/pdf/ln/n59/a04n59.pdf>. Acesso em: 23 set. 2006.

MADUREIRA, Miriam M. S. de. Introducción. In: HONNETH, Axel. Crítica del agravio moral: patologías de la sociedad contemporánea. Buenos Aires: Fondo de Cultura Económica; Universidad Autónoma Metropolitana, 2009. p. 5-16.

MARSHALL, Thomas Humphrey. Cidadania, classe social e status. Rio de Janeiro: Zahar, 1967.

MEAD, George H. Espíritu, persona y sociedad: desde el punto de vista del conductismo social. 4. reimp. Madri: Paidós, 2010. 
OGANDO, Ana Carolina; ASSIS, Mariana P. F. Reconhecimento e direitos individuais: categorias em tensão e o caso das mulheres brasileiras. In: SEMINÁRIO INTERNACIONAL FAZENDO GÊNERO, 7., 28-30 ago. 2006, Florianópolis, UFSC. Disponível em: <www.fazendogenero.ufsc.br/7/artigos/O/ Ogando-Assis_34.pdf>. Acesso: 17 set. 2006.

OIT. Organização Internacional do Trabalho. Agenda nacional de trabalho decente. Brasília: OIT, 2006.

PAUGAM, Serge. Desqualificação social: ensaio sobre a nova pobreza. São Paulo: Educ \& Cortez, 2003.

PINTO, Celi R. J. Notas sobre a controvérsia Fraser-Honneth informada pelo cenário brasileiro. Lua Nova, São Paulo, n. 74, p. 35-58, 2008. Disponível em: <www.scielo.br/pdf/ln/n74/03.pdf>. Acesso em: 13 dez. 2008.

SADER, Eder. Quando os novos personagens entram em cena. São Paulo: Paz e Terra, 1988.

SILVA, Josué P. Teoria crítica na modernidade tardia: sobre a relação entre redistribuição e reconhecimento. In: ENCONTRO ANUAL DA ANPOCS, XXIX, out. 2005, Caxambu. Anais... Caxambu, 2005.

SPOSATI, Aldaíza. Assistência na trajetória das políticas sociais brasileiras: uma questão em análise. 8. ed. São Paulo: Cortez, 2003.

TAYLOR, Charles. Argumentos filosóficos. São Paulo: Loyola, 2000.

TELLES, Vera da S. Pobreza e cidadania. São Paulo: Editora 34, 2001.

TELLES, Vera da S. Questão social: afinal, do que se trata? São Paulo em Perspectiva, v. 10, n. 4, p. 85-95, 1996.

Alex Pizzio é docente no Programa de Pós-Graduação em Desenvolvimento Regional da Universidade Federal do Tocantins (UFT). Doutor em ciências sociais. E-mail: alexpizzio@uft.edu.br. 